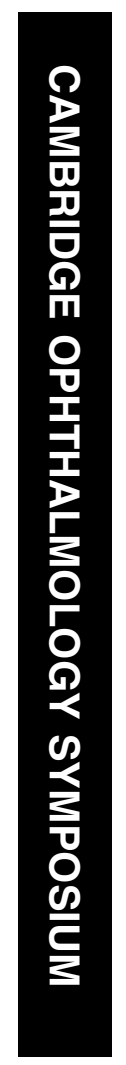

\title{
Management of patients with combined glaucoma and corneal transplant surgery
}

\begin{abstract}
Penetrating keratoplasty (PKP) is associated with an increased risk of secondary glaucoma. The development of glaucoma after PKP is an important risk factor for decreased corneal graft survival. The incidence of glaucoma after corneal transplant as well as the mechanism of developing increased intraocular pressure is reviewed in this paper. Treatments for postPKP glaucoma include medications, laser, and surgery. The most frequent surgical glaucoma intervention is implantation of a glaucomadrainage device. Recent advances in corneal transplantation surgery may help to decrease corneal failure and the risk of developing post-keratoplasty glaucoma.
\end{abstract}

Bascom Palmer Eye Institute, University of Miami School of Medicine, Miami, FL, USA

Correspondence: RK Lee, Bascom Palmer Eye Institute, University of Miami School of Medicine, 900 NW 17th Street,

Miami, FL 33136, USA

Tel: + 1305547 3686;

Fax: + 13055473658 ;

E-mail: rlee@

med.miami.edu

Received: 27 October 2008 Accepted in revised form: 5 November 2008 Published online: 16 January 2009

The authors have no proprietary or financial interest in the work discussed in this paper. RK Lee is supported by $\mathrm{NIH}$ grant EY016775 and the American Health Assistance Foundation - Glaucoma Research Foundation.
Eye (2009) 23, 1972-1979; doi:10.1038/eye.2008.377;

published online 16 January 2009

Keywords: glaucoma; corneal transplant; surgery

\section{Introduction}

Advances in keratoplasty surgical techniques may help to decrease the incidence of secondary glaucoma after keratoplasty surgery. The development of glaucoma after penetrating keratoplasty (PKP) can lead to devastating longterm complications, which are often sight threatening and challenging to treat. Patients with glaucoma after corneal transplants often respond poorly to medications and laser treatment and require surgical intervention not only to lower the intraocular pressure and preserve the optic nerve, but also to improve the survival of the corneal graft. This paper reviews the incidence, mechanism, and treatment of secondary glaucoma associated with corneal transplantation. Current trends in corneal transplantation and glaucoma surgery are also discussed.
M Banitt and RK Lee

Trends in corneal transplant surgery

In clinical series from around the world, primary indications for PKP include visually significant corneal scarring secondary to keratoconus and bullous keratopathy. ${ }^{1-10}$ An important trend associated with improvements in cataract surgery techniques and the introduction of intraocular lenses has been a decline in aphakic bullous keratopathy (ABK) and an increase in pseudophakic bullous keratopathy (PBK). ${ }^{8,11-14}$ After cataract surgery techniques evolved and phacoemulsification technology improved in the 1990s, pseudophakic corneal oedema rates have decreased..$^{5-8,11,14-16}$

Descemet stripping automated endothelial keratoplasty (DSAEK) is a significant change in the approach to corneal transplantation involving the transplantation of an endothelial cell layer (with a thin stromal layer) vs a full thickness corneal graft in PKP. DSAEK has rapidly replaced PKP as the preferred method of corneal transplantation in eyes with PBK and Fuchs' corneal dystrophy. The Eye Bank Association of America reported an increase in corneal transplants from 48298 to 50122 from 2005 to 2007. In this same time period, the number of corneal endothelial transplant surgeries increased exponentially from 1429 to $14159 .^{17}$

Increased incidence of glaucoma after penetrating keratoplasty

Irvine and Kaufman first reported a higher incidence of elevated IOP after PKP noting intraocular pressures higher than $25 \mathrm{mmHg}$ in $37 \%$ of phakic eyes and $88 \%$ in aphakic eyes during the first post-operative week after corneal transplant surgery. ${ }^{18}$ The incidence of glaucoma after PKP varies with the indication 
for PKP. Increased IOP develops most frequently after PKP for ABK and less frequently for eyes with Fuchs' corneal dystrophy and keratoconus. ${ }^{19-27}$ In a series of 502 corneal transplant patients reported by Foulks in 1987, glaucoma developed in 18\% of all patients studied: $39 \%$ in patients who were aphakic, $8 \%$ in patients who had no history of glaucoma, and $80 \%$ in patients who had a prior history of glaucoma. ${ }^{19}$ In a series of 1122 patients from 1992, Kirkness and Ficker ${ }^{23}$ reported that $1 \%$ of patients with keratoconus, $3 \%$ of patients with corneal dystrophies, and $29 \%$ of patients with bullous keratopathy developed elevated IOP following PKP. In 1998, Ing reported the risk of developing glaucoma postPKP was 21\% in this surgical series of 394 patients: $1 \%$ in patients with keratoconus and up to $44 \%$ in patients with PBK. ${ }^{21}$

Other risk factors for the development of glaucoma after PKP include pre-existing glaucoma, the presence of peripheral anterior synechiae, corneal re-grafting, a history of ocular trauma, and combined PKP and cataract extraction surgery. ${ }^{19,21-23,28,29}$ Simmons reported a fourfold increased relative risk for developing glaucoma post-keratoplasty in patients with pre-existing glaucoma vs those without a prior history of glaucoma. ${ }^{30}$ Sihota reported a post-keratoplasty incidence of glaucoma of $10.6 \%$ in his series of 747 patients, $13 \%$ of whom underwent repeat PK for a failed corneal graft. ${ }^{31}$

\section{Mechanisms of post-keratoplasty glaucoma}

Although increased IOP after PKP can develop in eyes with open or closed angles, peripheral anterior synchiae is present in $87 \%$ of patients post-PKP. ${ }^{23,28}$ Distortion of the angle, anterior and posterior to the trabecular meshwork, has also been implicated as a cause for increased IOP after PKP. Anterior to the angle, tight and long sutures cause distortion, which leads to corneal oedema and distortion of the trabecular meshwork. Posterior to the angle, loss of fixation normally afforded by the ciliary body-lens-support system allows for collapse of the TM. ${ }^{32,33}$ In our experience, peripheral anterior synechiae secondary to corneal transplantation leads to progressive angle closure glaucoma that is often difficult to treat with medications or laser and frequently requires surgical intervention for adequate IOP control.

Corneal transplant donor size may also affect postkeratoplasty IOP. Using oversized donor tissue may decrease the incidence of increased IOP after PKP in the early post-operative course and, possibly in the long term, but data supporting this is limited. ${ }^{32-35}$ Postsurgical glaucoma can be caused by pupillary block, iritis, haemorrhage, steroid response, malignant glaucoma, or retained viscoelastic. The use of steroids is often a double-edged sword as it is used to prevent graft rejection, but may lead to steroid response glaucoma in susceptible patients.

\section{Medical management of post-keratoplasty glaucoma}

Topical medications should be used with full awareness of their inherent risks and benefits in mind. Most topical medications have preservatives, which can lead to punctate epithelialopathy. Timolol is currently manufactured in a non-preserved formulation. Briminodine is preserved with Purite ${ }^{\mathbb{R}}$ and travoprost has a formulation preserved with Sofzia ${ }^{\circledR}$ instead of benzalkonium chloride.

The most commonly used and successful glaucoma medications are topical beta-blockers and alphaadrenergic agonists. Prostaglandins are effective in lowering the IOP, but case reports of increased incidence of inflammation associated with their use may compromise graft outcome and visual outcome if cystoid macular oedema develops. Prostaglandin agonists should also be used with caution in patients with a history of herpetic disease as Wand reported an association between latanoprost and recurrence of herpetic keratitis. ${ }^{36}$ We do not hesitate to use prostaglandin agonists in patients with post-keratoplasty glaucoma, especially if the alternative is surgical intervention.

The use of miotics is usually ineffective and not recommended in the early post-operative period as pilocarpine causes break-down of the blood-aqueous barrier and shallows the anterior chamber with subsequent intraocular inflammation and potential development of peripheral anterior synchiae. Carbonic anhydrase inhibitors (CAIs) can be used topically or systemically. Although carbonic anhydrase enzyme is expressed by the corneal endothelium and is associated with endothelial pump function, the effect of CAIs on the graft is likely to be clinically significant only if the graft is near failure. ${ }^{37,38}$

\section{Surgical management of post-keratoplasty glaucoma}

\section{Cyclodestructive procedures}

Cyclodestruction was the first attempted surgical treatment for post-keratoplasty glaucoma. By ablating a portion of the ciliary body, IOP is lowered by decreasing aqueous humour production. Destruction of the ciliary body can be achieved through transscleral application of cryotherapy or transscleral or endoscopic delivery of diode, krypton or neodymium:yttrium-aluminumgarnet (Nd:YAG) laser.

Treatment success, defined as an IOP of less than $21 \mathrm{mmHg}$ after a single application of laser, has recently 
been reported to be between 63-97\%. ${ }^{39-44}$ However, multiple treatments may be necessary and graft failure rates have been reported to be between 17 and $44 \% .{ }^{39-44}$ With 5-year follow-up, Beiran reported successful IOP reduction in patients with post-keratoplasty glaucoma using transscleral Nd:YAG laser in $63 \%$ of the patients. Fifty-six percent of these patients had clear grafts after 5 years. ${ }^{40}$ More recent studies on the use of diode laser to control post-keratoplasty glaucoma show a single treatment success rate of $72 \%$ after 12 months with no cases of graft failure or phthisis bulbi. ${ }^{43}$ In a small series, Ayyala reported no differences between trabeculectomy with mitomycin C, cyclophotocoagulation, and glaucoma shunt procedures to control glaucoma after keratoplasty. ${ }^{39}$

\section{Laser trabeculoplasty}

Argon laser trabeculoplasty has been reported to successfully treat post-keratoplasty glaucoma. ${ }^{45}$ Use of this modality is often limited by the formation of PAS after keratoplasty. Poor visibility of the trabecular meshwork through the corneal transplant may also limit its use as the laser may be applied ineffectively, possibly resulting in further angle closure. Use of selective laser trabeculoplasty is also limited by visibility of the trabecular meshwork. Both procedures have limited data to support their efficacy in glaucoma following keratoplasty, and we typically do not use laser trabeculoplasty for treatment of post-keratoplasty glaucoma.

\section{Trabeculectomy}

Trabeculectomy with and without mitomycin- $\mathrm{C}$ has been shown to be successful in controlling intraocular pressure after keratoplasty (Table 1). ${ }^{39,46-52}$ The use of anti-metabolites improves IOP control and the success of trabeculectomy. Overall, the success rates for IOP control range from $87 \%$ (14 of 16 eyes) with 1-year follow-up to
$50 \%$ (12 of 24 eyes) after 2 years of follow-up based on various small studies. ${ }^{46,51}$ Graft clarity has been reported to be $60 \%$ after 2 years in a series of 24 patients and $62 \%$ after 22 months in a series of 26 patients. ${ }^{50,51}$ In postkeratoplasty patients with a trabeculectomy, glaucoma medications are frequently required for IOP control, with further glaucoma surgery often necessary. ${ }^{50-52}$

\section{Glaucoma drainage implant}

The most common treatment for glaucoma after keratoplasty when medications have proven to be insufficient is implantation of a tube shunt. Many studies have evaluated the efficacy of drainage implants, while evaluating graft clarity (Table 2). ${ }^{53-66}$ Glaucoma drainage implants (GDIs) are possibly the most successful modality for control of IOP after the fewest treatment procedures. ${ }^{39,44,64}$ IOP control has been reported to be $62-96 \%$ after 2 years of follow-up. ${ }^{54,58}$ The rate of graft failure has been reported to be $35-74 \%$ after 2 years of follow-up. ${ }^{59,60}$

The optimal location for the drainage tube remains controversial. The most common location for tube placement is in the anterior chamber. Several authors have evaluated the success rates of different tubeplacement locations. ${ }^{53,54,67}$ At 1 year, Arroyave found no difference in IOP control between the anterior chamber and pars plana tube placement, but the corneal grafts remained clear in only $48 \%$ of patients with tubes inserted into the anterior chamber vs $83 \%$ of patients with tubes placed in the pars plana. Sidoti studied 34 eyes with pars plana tube insertion and found IOP controlled in only $62 \%$ of eyes after 2 years, with clear grafts in $41 \%$ of the eyes. Sidoti also observed a higher rate of posterior segment complications as might be expected in eyes undergoing pars plana vitrectomy (allowing for pars plana tube insertion). Ritterband studied 83 eyes in which the drainage tube was either placed in the pars plana primarily or moved from the anterior chamber to the pars plana at the time of PKP. Ritterband reported

Table 1 Studies of trabeculectomy in post-keratoplasty glaucoma

\begin{tabular}{lcclcr}
\hline Author & Number of eyes & Mean follow-up (months) & Mitomycin & Success rate for IOP control (\%) & Graft-survival rate (\%) \\
\hline Sharma $^{46}$ & 16 & 14 & Yes & 94 & 88 \\
Chowers $^{47}$ & 11 & 15 & Yes & 91 & 82 \\
Insler $^{48}$ & 7 & 16 & None & 71 & 86 \\
Figueiredo $^{49}$ & 9 & 16 & Yes & 67 & 78 \\
Ayyala $^{50}$ & 17 & 18 & Yes & 67 & 85 \\
Ishioka $^{50}$ & 34 & 22 & 26 MMC & 62 & 62 \\
WuDunn $^{51}$ & 24 & & 8 No MMC & 50 & 60 \\
Gilvarry & 35 & 24 & Yes & 51 & 66 \\
\hline
\end{tabular}


Table 2 Studies of glaucoma drainage implant in post-keratoplasty glaucoma

\begin{tabular}{lcccc}
\hline Author & Number of eyes & Mean follow-up (months) & Success rate for IOP control (\%) & Graft-survival rate (\%) \\
\hline Arroyave $^{53}$ & 72 & 12 & 92 & 57 \\
$\quad$ Arroyave in anterior chamber $^{53}$ & 54 & 12 & 89 & 48 \\
Arroyave in vitreous cavity $^{53}$ & 18 & 12 & 100 & 83 \\
Sidoti $^{54}$ (only vitreous cavity) & 34 & 12 & 85 & 61 \\
McDonnell $^{55}$ & 17 & 13 & 71 & 71 \\
Joos $^{56}$ (only vitreous cavity) & 9 & 17 & 100 & 89 \\
Coleman $^{57}$ & 31 & 20 & 52 & 62 \\
Sherwood $^{58}$ & 26 & 22 & 96 & 58 \\
Rapuano $^{59}$ & 46 & 23 & 96 & 65 \\
Alvarenga $^{60}$ & 40 & 24 & 63 & 56 \\
Al-Torbak & 25 & 25 & 86 & 50 \\
Beebe $^{62}$ & 35 & 25 & 86 & 80 \\
Kirkness $^{63}$ & 20 & 26 & 82 & 50 \\
Kwon $^{64}$ & 55 & 36 & & 55 \\
\hline
\end{tabular}

IOP control in $83 \%$ of patients (20 of 24 patients) and graft clarity in $59 \%$ of patients (19 of 32 patients) after 2 years. Shunt tubes can become occluded when placed in either the anterior chamber or the vitreous cavity. However, inserting the tube into the vitreous cavity significantly reduces any interaction between the graft and the tube, which likely leads to improved graft survival as shown by Arroyave. ${ }^{53}$ Placement of the tube into the vitreous cavity necessitates a complete vitrectomy with careful removal of the vitreous skirt, thereby preventing vitreous from occluding the tube. One advantage with a well-placed tube in the anterior chamber away from the cornea is convenient observation of the tube tip for occlusion at the slit lamp and easy access for laser and needling procedures to remove any tissues if the tube tip is blocked.

Graft survival in eyes with GDI placed before, simultaneously with, or after PKP has been studied and show mixed results. Kwon and Beebe reported better graft survival when the drainage implant was inserted after corneal transplantation. ${ }^{62,64}$ Alvarenga and Arroyave both reported no association between graft survival and timing of glaucoma drainage placement. ${ }^{53,60}$ Rapuano showed improved graft survival with glaucoma drainage implant surgery earlier to or at the same time as corneal transplantation. ${ }^{59}$ The differences in these studies are likely explained by the severity of glaucoma. Patients with pre-existing glaucoma have a known risk factor for graft failure and are more likely to have uncontrolled IOP after PKP. ${ }^{28,30,68,69}$

\section{New trends in keratoplasty surgery}

As mentioned earlier, fewer keratoplasties are being performed for ABK. As aphakic patients have the highest incidence of post-keratopathy glaucoma, a trend towards reduced overall incidence of glaucoma in postkeratoplasty patients is anticipated.

The newest trend in keratoplasty is towards endothelial keratoplasty (EK) or DSAEK. Although the technique is still being refined and may undergo further advancement to involve transplantation of only Descemet's membrane instead of Descemet's membrane and stroma, the number of EK surgeries being performed is increasing rapidly. In 2005, EK represented only 3\% of all transplants, whereas in 2007 EK accounted for $28 \%$ of all corneal transplant performed in the United States.

Although limited published information is currently available regarding the development of glaucoma after DSAEK,${ }^{70-75}$ the incidence of glaucoma following DSAEK will likely remain low for several reasons. Fuchs' corneal dystrophy, one of the most common indications for DSAEK, has shown a low incidence of post-keratoplasty glaucoma as discussed above. In DSEAK, sutures are used only to close paracentesis(es) and the main incision, and should therefore result in less angle distortion anterior to the TM when compared with PKP. Unless improperly sized, a DSEAK donor lenticle should not contribute to crowding of the anterior chamber angle.

Air bubbles causing pupillary block glaucoma have been observed with DSAEK surgery. However, Price ${ }^{73}$ has reported only one case in his series of 200. DSAEK has been successfully carried out in eyes with iridocorneal endothelial syndrome, in which eyes often have pre-existing glaucoma and the diseased layer of the cornea is limited to the endothelium. ${ }^{74}$

In terms of the management of IOP after EK, the thicker central corneal thickness seen after DSAEK does not appear to give falsely elevated Goldmann applanation tonometry readings. Thus, the management of IOP after DSAEK should not be affected by the thicker central cornea. ${ }^{75}$ The location of glaucoma drainage implant tube insertion in eyes that have already 
undergone or will undergo DSAEK has not been studied. Whether or not graft clarity is different when the drainage tube is placed in the pars plana or in the anterior chamber should be determined in the future. DSAEK has been suggested to have a lower incidence of graft rejection ${ }^{76}$ and possibly a lower risk of postkeratoplasty glaucoma.

An alternative to PKP-transplant patients with a high risk of corneal graft failure is the use of a

keratoprosthesis. Glaucoma has been reported to occur in between $58-72 \%$ of patients who have received a Boston keratoprosthesis. ${ }^{77-79}$ In one series of patients with aniridia, 14 of 15 (93\%) patients had pre-existing glaucoma. Glaucoma surgery was performed in 4 of 15 (27\%) patients before to implantation of the

keratoprosthesis. An additional four patients required post-keratoprosthesis glaucoma surgery, primarily GDI. The mechanism of glaucoma is thought to be related to eyes having had surgeries earlier due to secondary angle closure caused by inflammation or compromise of the angle due to the size and location of the keratoprosthesis back plate in relation to the iris and angle structures. In ocular surface cicatrizing diseases, thick capsules may form around the glaucoma drainage plate. A novel technique has been shown to redirect the shunt tube into extraorbital locations. ${ }^{80}$

An advance in PKP has been the use of the femtosecond laser to cut both the host and donor buttons. ${ }^{81-85}$ This new technique is an attempt to improve wound architecture and limit astigmatism as the wounds can be shaped (zig-zag, top-hat, or mushroom patterns), possibly allowing for closure with fewer sutures and/or tissue glue. In theory, the use of fewer sutures may limit angle distortion and lead to lower incidence of postoperative glaucoma. New advances may make deep anterior lamellar keratoplasty the surgery of choice for anterior corneal diseases, including keratoconus and stromal scarring. Anwar described a technique of using a 'big bubble' to separate Descemet's membrane from the corneal stroma. ${ }^{86}$ The femtosecond laser has been utilized to cut the host and donor tissues for anterior lamellar keratoplasty and can be performed without sutures. ${ }^{87}$ Lamellar keratoplasty has the advantage of maintaining the patient's own endothelium and will minimally affect the angle architecture. This should lead to a reduced incidence of post-keratoplasty glaucoma, at least due to architectural changes secondary to keratoplasty.

\section{Summary}

Glaucoma after corneal transplantation remains difficult to manage and a significant barrier to optimal visual outcome and corneal graft survival. Current treatments have varied, with significant side effects and complications. Although the literature includes many studies on the treatment of glaucoma after keratoplasty, many of these studies have small numbers of patients, limited follow-up, and different criteria for defining successful outcomes.

As techniques in corneal transplantation evolve, grafts should remain clear longer, with a lower incidence of glaucoma. When glaucoma does occur, it is our experience that it should be treated promptly. We typically initiate topical medical therapy and choose medications balancing risks and benefits with the patient's co-morbidities. We have found laser trabeculoplasty to be usually ineffective in treatment of post-keratoplasty glaucoma, especially if peripheral anterior synecheia is present. If surgical intervention is required, our preference is to perform GDI surgery with tube placement in accordance with the patient's anterior and posterior segment findings. When patients present with medically uncontrolled IOP and corneal opacity necessitating PKP, it is our strong preference to perform glaucoma surgery, usually GDI first to control the pressure. After the IOP and post-operative inflammation is controlled, we recommend proceeding with corneal transplant surgery. Although laser cyclodestruction has been reserved for eyes with limited visual prognosis, it should likely be given further consideration. Finally, we believe that newer corneal transplantation surgeries, such as DSAEK, will probably result in lower rates of corneal rejection secondary to improved anterior segment architectural anatomy and decreased rates of secondary glaucoma.

\section{References}

1 Al-Towerki AE, Gonnah el S, Al-Rajhi A, Wagoner MD. Changing indications for corneal transplantation at the King Khaled Eye Specialist Hospital (1983-2002). Cornea 2004; 23(6): 584-588.

2 Chipman ML, Slomovic AS, Rootman D, Dixon WS. Changing risk for early transplant failure: data from the Ontario Corneal Recipient Registry. Can J Ophthalmol 1993; 28(6): 254-258.

3 Claesson M, Armitage WJ, Fagerholm P, Stenevi U. Visual outcome in corneal grafts: a preliminary analysis of the Swedish Corneal Transplant Register. Br J Ophthalmol 2002; 86(2): 174-180.

4 Cursiefen C, Kuchle M, Naumann GO. Changing indications for penetrating keratoplasty: histopathology of 1,250 corneal buttons. Cornea 1998; 17(5): 468-470.

5 Damji KF, Rootman J, White VA, Dubord PJ, Richards JS. Changing indications for penetrating keratoplasty in Vancouver, 1978-87. Can J Ophthalmol 1990; 25(5): 243-248.

6 Inoue K, Amano S, Oshika T, Sawa M, Tsuru T. A 10-year review of penetrating keratoplasty. Jpn J Ophthalmol 2000; 44(2): 139-145.

7 Liu E, Slomovic AR. Indications for penetrating keratoplasty in Canada, 1986-1995. Cornea 1997; 16(4): 414-419. 
8 Maeno A, Naor J, Lee HM, Hunter WS, Rootman DS. Three decades of corneal transplantation: indications and patient characteristics. Cornea 2000; 19(1): 7-11.

9 Tan DT, Janardhanan P, Zhou H, Chan YH, Htoon HM, Ang $\mathrm{LP}$ et al. Penetrating keratoplasty in Asian eyes: the Singapore Corneal Transplant Study. Ophthalmology 2008; 115(6): 975-982 e1.

10 Vail A, Gore SM, Bradley BA, Easty DL, Rogers CA. Corneal transplantation in the United Kingdom and Republic of Ireland. Br J Ophthalmol 1993; 77(10): 650-656.

11 Cosar CB, Sridhar MS, Cohen EJ, Held EL, Alvim Pde T, Rapuano $\mathrm{CJ}$ et al. Indications for penetrating keratoplasty and associated procedures, 1996-2000. Cornea 2002; 21(2): 148-151.

12 Darlington JK, Adrean SD, Schwab IR. Trends of penetrating keratoplasty in the United States from 1980 to 2004. Ophthalmology 2006; 113(12): 2171-2175.

13 Flowers CW, Chanq KY, McLeod SD, Irvine JA, McDonnell $\mathrm{PJ}, \mathrm{Rao} \mathrm{N}$ et al. Changing indications for penetrating keratoplasty, 1989-1993. Cornea 1995; 14(6): 583-588.

14 Lois N, Kowal VO, Cohen EJ, Rapuano CJ, Gault JA, Raber IM et al. Indications for penetrating keratoplasty and associated procedures, 1989-1995. Cornea 1997; 16(6): 623-629.

15 Aiken-O'Neill P, Mannis MJ. Summary of corneal transplant activity Eye Bank Association of America. Cornea 2002; 21(1): 1-3.

16 Thompson Jr RW, Price MO, Bowers PJ, Price Jr FW. Long-term graft survival after penetrating keratoplasty. Ophthalmology 2003; 110(7): 1396-1402.

17 Eye Banking Statistical ReportEye Bank Association of America: Washington, DC2007.

18 Irvine AR, Kaufman HE. Intraolar pressure following penetrating keratoplasty. Am J Ophthalmol 1969; 68(5): 835-844.

19 Foulks GN. Glaucoma associated with penetrating keratoplasty. Ophthalmology 1987; 94(7): 871-874.

20 Goldberg DB, Schanzlin DJ, Brown SI. Incidence of increased intraocular pressure after keratoplasty. $A m \mathrm{~J}$ Ophthalmol 1981; 92(3): 372-377.

21 Ing JJ, Ing HH, Nelson LR, Hodge DO, Bourne WM. Ten-year postoperative results of penetrating keratoplasty. Ophthalmology 1998; 105(10): 1855-1865.

22 Karesh JW, Nirankari VS. Factors associated with glaucoma after penetrating keratoplasty. Am J Ophthalmol 1983; 96(2): 160-164.

23 Kirkness CM, Ficker LA. Risk factors for the development of postkeratoplasty glaucoma. Cornea 1992; 11(5): 427-432.

24 Vail A, Gore SM, Bradley BA, Easty DL, Rogers CA, Armitage WJ. Conclusions of the corneal transplant follow up study. Collaborating Surgeons. Br J Ophthalmol 1997; 81(8): 631-636.

25 Nguyen NX, Langenbucher A, Seitz B, Küchle M, Naumann GO. Impact of increased intraocular pressure on long-term corneal endothelial cell density after penetrating keratoplasty. Ophthalmologica 2002; 216(1): 40-44.

26 Polack FM. Glaucoma in keratoplasty. Cornea 1988; 7(1): 67-70.

27 Franca ET, Arcieri ES, Arcieri RS, Rocha FJ. A study of glaucoma after penetrating keratoplasty. Cornea 2002; 21(3): 284-288.

28 Maguire MG, Stark WJ, Gottsch JD, Stulting RD, Sugar A, Fink NE et al. Risk factors for corneal graft failure and rejection in the collaborative corneal transplantation studies.
Collaborative Corneal Transplantation Studies Research Group. Ophthalmology 1994; 101(9): 1536-1547.

29 Waring III GO, Stulting RD, Street D. Penetrating keratoplasty for pseudophakic corneal edema with exchange of intraocular lenses. Arch Ophthalmol 1987; 105(1): $58-62$.

30 Simmons RB, Stern RA, Teekhasaenee C, Kenyon KR. Elevated intraocular pressure following penetrating keratoplasty. Trans Am Ophthalmol Soc 1989; 87: 79-91; discussion 3 .

31 Sihota R, Sharma N, Panda A, Aggarwal HC, Singh R. Post-penetrating keratoplasty glaucoma: risk factors, management and visual outcome. Aust N Z J Ophthalmol 1998; 26(4): 305-309.

32 Olson RJ, Kaufman HE. A mathematical description of causative factors and prevention of elevated intraocular pressure after keratoplasty. Invest Ophthalmol Vis Sci 1977; 16(12): 1085-1092.

33 Zimmerman T, Olson R, Waltman S, Kaufman H. Transplant size and elevated intraocular pressure. Postkeratoplasty. Arch Ophthalmol 1978; 96(12): 2231-2233.

34 Bourne WM, Davison JA, O'Fallon WM. The effects of oversize donor buttons on postoperative intraocular pressure and corneal curvature in aphakic penetrating keratoplasty. Ophthalmology 1982; 89(3): 242-246.

35 Heidemann DG, Sugar A, Meyer RF, Musch DC. Oversized donor grafts in penetrating keratoplasty. A randomized trial. Arch Ophthalmol 1985; 103(12): 1807-1811.

36 Wand M, Gilbert CM, Liesegang TJ. Latanoprost and herpes simplex keratitis. Am J Ophthalmol 1999; 127(5): 602-604.

37 Giasson CJ, Nguyen TQ, Boisjoly HM, Lesk MR, Amyot M, Charest M. Dorzolamide and corneal recovery from edema in patients with glaucoma or ocular hypertension. Am J Ophthalmol 2000; 129(2): 144-150.

38 Konowal A, Morrison JC, Brown SV, Cooke DL, Maguire LJ, Verdier DV et al. Irreversible corneal decompensation in patients treated with topical dorzolamide. Am J Ophthalmol 1999; 127(4): 403-406.

39 Ayyala RS, Pieroth L, Vinals AF, Goldstein MH, Schuman JS, Netland PA et al. Comparison of mitomycin C trabeculectomy, glaucoma drainage device implantation, and laser neodymium:YAG cyclophotocoagulation in the management of intractable glaucoma after penetrating keratoplasty. Ophthalmology 1998; 105(8): 1550-1556.

40 Beiran I, Rootman DS, Trope GE, Buys YM. Long-term results of transscleral Nd:YAG cyclophotocoagulation for refractory glaucoma postpenetrating keratoplasty. J Glaucoma 2000; 9(3): 268-272.

41 Binder PS, Abel Jr R, Kaufman HE. Cyclocryotherapy for glaucoma after penetrating keratoplasty. Am J Ophthalmol 1975; 79(3): 489-492.

42 Munoz FJ, Rebolleda G. Cyclophotocoagulation for glaucoma after penetrating keratoplasty. Ophthalmology 1999; 106(4): 644-645.

43 Ocakoglu O, Arslan OS, Kayiran A. Diode laser transscleral cyclophotocoagulation for the treatment of refractory glaucoma after penetrating keratoplasty. Curr Eye Res 2005; 30(7): 569-574

44 Topouzis F, Yu F, Coleman AL. Factors associated with elevated rates of adverse outcomes after cyclodestructive procedures versus drainage device procedures. Ophthalmology 1998; 105(12): 2276-2281.

45 Van Meter WS, Allen RC, Waring III GO, Stulting RD. Laser trabeculoplasty for glaucoma in aphakic and pseudophakic 
eyes after penetrating keratoplasty. Arch Ophthalmol 1988 106(2): 185-188.

46 Sharma A, Kumar S, Ram J, Gupta A. Trabeculectomy with mitomycin-C for postkeratoplasty glaucoma: a preliminary study. Ophthalmic Surg Lasers 1997; 28(11): 891-895.

47 Chowers I, Ticho U. Mitomycin-C in combined or two-stage procedure trabeculectomy followed by penetrating keratoplasty. J Glaucoma 1999; 8(3): 184-187.

48 Insler MS, Cooper HD, Kastl PR, Caldwell DR. Penetrating keratoplasty with trabeculectomy. Am J Ophthalmol 1985; 100(4): 593-595.

49 Figueiredo RS, Araujo SV, Cohen EJ, Rapuano CJ, Katz LJ, Wilson RP. Management of coexisting corneal disease and glaucoma by combined penetrating keratoplasty and trabeculectomy with mitomycin-C. Ophthalmic Surg Lasers 1996; 27(11): 903-909.

50 Ishioka M, Shimazaki J, Yamagami J, Fujishima H, Shimmura S, Tsubota K. Trabeculectomy with mitomycin C for post-keratoplasty glaucoma. Br J Ophthalmol 2000; 84(7): 714-717.

51 WuDunn D, Alfonso E, Palmberg PF. Combined penetrating keratoplasty and trabeculectomy with mitomycin C. Ophthalmology 1999; 106(2): 396-400.

52 Gilvarry AM, Kirkness CM, Steele AD, Rice NS, Ficker LA. The management of post-keratoplasty glaucoma by trabeculectomy. Eye 1989; 3(Pt 6): 713-718.

53 Arroyave CP, Scott IU, Fantes FE, Feuer WJ, Murray TG. Corneal graft survival and intraocular pressure control after penetrating keratoplasty and glaucoma drainage device implantation. Ophthalmology 2001; 108(11): 1978-1985.

54 Sidoti PA, Mosny AY, Ritterband DC, Seedor JA. Pars plana tube insertion of glaucoma drainage implants and penetrating keratoplasty in patients with coexisting glaucoma and corneal disease. Ophthalmology 2001; 108(6): 1050-1058.

55 McDonnell PJ, Robin JB, Schanzlin DJ, Minckler D, Baerveldt G, Smith RE et al. Molteno implant for control of glaucoma in eyes after penetrating keratoplasty. Ophthalmology 1988; 95(3): 364-369.

56 Joos KM, Lavina AM, Tawansy KA, Agarwal A. Posterior repositioning of glaucoma implants for anterior segment complications. Ophthalmology 2001; 108(2): 279-284.

57 Coleman AL, Mondino BJ, Wilson MR, Casey R. Clinical experience with the Ahmed Glaucoma Valve implant in eyes with prior or concurrent penetrating keratoplasties. Am J Ophthalmol 1997; 123(1): 54-61.

58 Sherwood MB, Smith MF, Driebe Jr WT, Stern GA, Beneke JA, Zam ZS. Drainage tube implants in the treatment of glaucoma following penetrating keratoplasty. Ophthalmic Surg 1993; 24(3): 185-189.

59 Rapuano CJ, Schmidt CM, Cohen EJ, Rajpal RK, Raber IM, Katz LJ et al. Results of alloplastic tube shunt procedures before, during, or after penetrating keratoplasty. Cornea 1995; 14(1): 26-32.

60 Alvarenga LS, Mannis MJ, Brandt JD, Lee WB, Schwab IR, Lim MC. The long-term results of keratoplasty in eyes with a glaucoma drainage device. Am J Ophthalmol 2004; 138(2): 200-205.

61 Al-Torbak AA. Outcome of combined Ahmed glaucoma valve implant and penetrating keratoplasty in refractory congenital glaucoma with corneal opacity. Cornea 2004; 23(6): 554-559.

62 Beebe WE, Starita RJ, Fellman RL, Lynn JR, Gelender H. The use of Molteno implant and anterior chamber tube shunt to encircling band for the treatment of glaucoma in keratoplasty patients. Ophthalmology 1990; 97(11): 1414-1422.

63 Kirkness CM, Ling Y, Rice NS. The use of silicone drainage tubing to control post-keratoplasty glaucoma. Eye 1988; 2(Pt 5): 583-590.

64 Kwon YH, Taylor JM, Hong S, Honkanen RA, Zimmerman $\mathrm{MB}$, Alward WL et al. Long-term results of eyes with penetrating keratoplasty and glaucoma drainage tube implant. Ophthalmology 2001; 108(2): 272-278.

65 Al-Torbak A. Graft survival and glaucoma outcome after simultaneous penetrating keratoplasty and ahmed glaucoma valve implant. Cornea 2003; 22(3): 194-197.

66 Hodkin MJ, Goldblatt WS, Burgoyne CF, Ball SF, Insler MS. Early clinical experience with the Baerveldt implant in complicated glaucomas. Am J Ophthalmol 1995; 120(1): 32-40.

67 Ritterband DC, Shapiro D, Trubnik V, Marmor M, Meskin S, Seedor J, et al., Cornea Glaucoma Implant Study Group (COGIS). Penetrating keratoplasty with pars plana glaucoma drainage devices. Cornea 2007; 26(9): 1060-1066.

68 Price MO, Thompson Jr RW, Price Jr FW. Risk factors for various causes of failure in initial corneal grafts. Arch Ophthalmol 2003; 121(8): 1087-1092.

69 Sit M, Weisbrod DJ, Naor J, Slomovic AR. Corneal graft outcome study. Cornea 2001; 20(2): 129-133.

70 Chen ES, Terry MA, Shamie N, Hoar KL, Friend DJ. Descemet-stripping automated endothelial keratoplasty: six-month results in a prospective study of 100 eyes. Cornea 2008; 27(5): 514-520.

71 Duarte MC, Herndon LW, Gupta PK, Afshari NA. DSEK in eyes with double glaucoma tubes. Ophthalmology 2008; 115(8): 1435, e1.

72 Mearza AA, Qureshi MA, Rostron CK. Experience and 12-month results of descemet-stripping endothelial keratoplasty (DSEK) with a small-incision technique. Cornea 2007; 26(3): 279-283.

73 Price Jr FW, Price MO. Descemet's stripping with endothelial keratoplasty in 200 eyes: early challenges and techniques to enhance donor adherence. J Cataract Refract Surg 2006; 32(3): 411-418.

74 Price MO, Price Jr FW. Descemet stripping with endothelial keratoplasty for treatment of iridocorneal endothelial syndrome. Cornea 2007; 26(4): 493-497.

75 Vajaranant TS, Price MO, Price FW, Wilensky JT, Edward DP. Intraocular pressure measurements following Descemet stripping endothelial keratoplasty. Am J Ophthalmol 2008; 145(5): 780-786.

76 Allan BD, Terry MA, Price Jr FW, Price MO, Griffin NB, Claesson M. Corneal transplant rejection rate and severity after endothelial keratoplasty. Cornea 2007; 26(9): 1039-1042.

77 Akpek EK, Harissi-Dagher M, Petrarca R, Butrus SI, Pineda II R, Aquavella JV et al. Outcomes of Boston keratoprosthesis in aniridia: a retrospective multicenter study. Am J Ophthalmol 2007; 144(2): 227-231.

78 Yaghouti F, Nouri M, Abad JC, Power WJ, Doane MG, Dohlman $\mathrm{CH}$. Keratoprosthesis: preoperative prognostic categories. Cornea 2001; 20(1): 19-23.

79 Zerbe BL, Belin MW, Ciolino JB. Results from the multicenter Boston Type 1 Keratoprosthesis Study. Ophthalmology 2006; 113(10): 1779 e1-7.

80 Rubin PA, Chang E, Bernardino CR, Hatton MP, Dohlman $\mathrm{CH}$. Oculoplastic technique of connecting a glaucoma valve 
shunt to extraorbital locations in cases of severe glaucoma. Ophthal Plast Reconstr Surg 2004; 20(5): 362-367.

81 Ignacio TS, Nguyen TB, Chuck RS, Kurtz RM, Sarayba MA. Top hat wound configuration for penetrating keratoplasty using the femtosecond laser: a laboratory model. Cornea 2006; 25(3): 336-340.

82 Jonas JB, Vossmerbaeumer U. Femtosecond laser penetrating keratoplasty with conical incisions and positional spikes. J Refract Surg 2004; 20(4): 397.

83 Meltendorf C, Schroeter J, Bug R, Kohnen T, Deller T. Corneal trephination with the femtosecond laser. Cornea 2006; 25(9): 1090-1092.

84 Seitz B, Brunner H, Viestenz A, Hofmann-Rummelt C, Schlötzer-Schrehardt U, Naumann GO et al. Inverse mushroom-shaped nonmechanical penetrating keratoplasty using a femtosecond laser. Am J Ophthalmol 2005; 139(5): 941-944.

85 Soong HK, Mian S, Abbasi O, Juhasz T. Femtosecond laserassisted posterior lamellar keratoplasty: initial studies of surgical technique in eye bank eyes. Ophthalmology 2005; 112(1): 44-49.

86 Anwar M, Teichmann KD. Big-bubble technique to bare Descemet's membrane in anterior lamellar keratoplasty. J Cataract Refract Surg 2002; 28(3): 398-403.

87 Yoo SH, Kymionis GD, Koreishi A, Ide T, Goldman D, Karp CL et al. Femtosecond laser-assisted sutureless anterior lamellar keratoplasty. Ophthalmology 2008; 115(8): 1303-1307, 7 e1. 